\title{
Visceral Adiposity Index and Prognostic Nutritional Index in Predicting Atrial Fibrillation after On-Pump Coronary Artery Bypass Operations: a Prospective Study
}

Mesut Engin'1, MD; Kadir Kaan Ozsin², MD; Muhammed Savran², MD; Orhan Guvenc³ , MD; Senol Yavuz², MD; Ahmet Fatih Ozyazicioglu², MD

DOI: $10.21470 / 1678-9741-2020-0044$

\begin{abstract}
Introduction: Rhythm problems are the most observed complications following coronary artery bypass grafting (CABG), the most common being postoperative atrial fibrillation (PoAF), with an incidence reaching $50 \%$ of the patients. In this study, we aimed to investigate the predictive importance of prognostic nutritional index (PNI) and visceral adiposity index (VAI) in predicting PoAF, which occurs after CABG accompanied by cardiopulmonary bypass.

Methods: Patients who underwent isolated CABG with cardiopulmonary bypass between June 15 and October 15, 2019, were prospectively included in the study. Patients who did not develop in-hospital PoAF were identified as Group 1, and those who did constituted Group 2.

Results: PoAF developed in 55 (27.6\%) patients (Group 2). The mean age of the 144 patients included in Group 1 and 55 patients in
\end{abstract}

Group 2 were $56.9 \pm 8.7$ and $64.3 \pm 10.2$ years, respectively $(P<0.001)$. In multivariate analysis Model 1, age (odds ratio [OR]: 1.084, confidence interval [Cl]: 1.010-1.176, $P=0.009)$, chronic obstructive

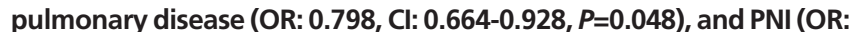
1.052, Cl: 1.015-1.379, $P=0.011)$ were determined as independent predictors for PoAF. In Model 2, age (OR: 1.078, Cl: 1.008-1.194, $P=0.012$ ), lymphocyte counts (OR: $0.412, C l: 0.374-0.778, P=0.032$ ), and VAI (OR: 1.516, Cl: 1.314-2.154, $P<0.001)$ were determined as independent predictors for PoAF.

Conclusion: In this study, we determined that low PNI, a simply calculable and cheap parameter, along with high VAI were risk factors for PoAF.

Keywords: Adiposity. Prognosis. Nutritional Assessment. Atrial Fibrillation. Waist Circumference. Lymphocyte Count. Postoperative Term.

Abbreviations, acronyms \& symbols

\begin{tabular}{llll}
\hline ACE-I & $=$ Angiotensin-converting enzyme inhibitor & HDL-C & = High-density lipoprotein cholesterol \\
AF & $=$ Atrial fibrillation & HT & = Hypertension \\
ARB & $=$ Angiotensin receptor blocker & ICU & $=$ Intensive care unit \\
AUC & = Areas under the curve & LDL-C & $=$ Low-density lipoprotein cholesterol \\
BMI & $=$ Body mass index & OR & $=$ Odds ratio \\
CABG & $=$ Coronary artery bypass grafting & PCI & $=$ Percutaneous coronary intervention \\
CCt & $=$ Cross-clamp time & PNI & $=$ Prognostic nutritional index \\
CI & $=$ Confidence interval & PoAF & $=$ Postoperative atrial fibrillation \\
COPD & $=$ Chronic obstructive pulmonary disease & ROC & $=$ Receiver-operating characteristic \\
CPB & $=$ Cardiopulmonary bypass & SD & $=$ Standard deviation \\
CRP & $=$ C-reactive protein & TG & $=$ Triglycerides \\
ECG & $=$ Electrocardiography & TPt & $=$ Total perfusion time \\
EuroSCORE II & $=$ European System for Cardiac Operative Risk & TSH & $=$ Thyroid-stimulating hormone \\
& Evaluation II & VAI & $=$ Visceral adiposity index \\
HDL & $=$ High-density lipoprotein & WC & $=$ Waist circumference
\end{tabular}

'Department of Cardiovascular Surgery, University of Health Sciences, Mehmet Akif Inan Training and Research Hospital, Karaköprü/Şanlıurfa, Turkey.

${ }^{2}$ Department of Cardiovascular Surgery, University of Health Sciences, Bursa Yuksek Ihtisas Training and Research Hospital, Bursa, Turkey.

${ }^{3}$ Department of Cardiovascular Surgery, Medical Faculty of Uludağ University, Bursa, Turkey.

This study was carried out at the Department of Cardiovascular Surgery, University of Health Sciences, Bursa Yuksek Ihtisas Training and Research Hospital, Bursa, Turkey.
Correspondence Address:

Mesut Engin

(iD) https://orcid.org/0000-0003-2418-5823

Department of Cardiovascular Surgery, University of Health Sciences, Mehmet Akif Inan Training and Research Hospital

Esentepe Town. Ertuğrul Street, Karaköprü/Şanlıurfa, Turkey - Zip Code: 63200

E-mail: mesut_kvc_cor@hotmail.com 


\section{INTRODUCTION}

Coronary artery bypass grafting (CABG) is a major surgery; hence, it should be performed with particular care and discipline. Combating postoperative complications is as important as surgical technique. Rhythm problems are the most observed complications following $C A B G$, the most common being postoperative atrial fibrillation (PoAF), with an incidence reaching $50 \%$ of the patients. Known risk factors for this condition are advanced age, low ejection fraction, chronic obstructive pulmonary disease (COPD), and thyroid hormone disorders ${ }^{[1]}$. A recent study has shown that it increases hospital costs by up to three times, and causes significant morbidity, such as thromboembolic problems and prolonged hospital admissions ${ }^{[2]}$.

Obesity is one of the most important problems of our era. High body mass index (BMI) has been shown as a risk factor in many studies in terms of its effects on outcomes after coronary surgery. It is known that increased $\mathrm{BMI}$ increases PoAF ${ }^{[3]}$. However, among cardiovascular risk factors, the usability of BMI is controversial, which is defined as the "obesity paradox"[4]. Abdominal obesity is thought to be a better predictor for cardiovascular diseases, a valuable indicator for it is the visceral adiposity index (VAI), found to be more sensitive and specific in terms of cardiovascular risk

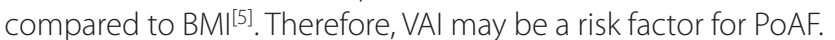

Prognostic nutritional index (PNI) is a parameter that can be calculated by albumin and lymphocyte count. The importance of albumin stems from its anti-inflammatory, antioxidant, and anticoagulant properties and its effects on osmotic pressure. Lymphopenia is associated with major adverse events in atherosclerotic cardiovascular diseases. Neutrophilia is induced by activation of cellular immunity by lymphocytes. The relationship between inflammatory biomarkers and PoAF has been demonstrated in many studies ${ }^{[6]}$. Therefore, PNI may be a risk factor for PoAF. Also PNI has been used to predict prognosis and poor outcome after myocardial infarction ${ }^{[7]}$, and in patients who underwent $C A B G^{[8]}$.

In this study, we aimed to investigate the importance of PNI and $\mathrm{VAl}$ in predicting POAF, which occurs after $\mathrm{CABG}$ operations accompanied by cardiopulmonary bypass (CPB).

\section{METHODS}

Patients who underwent isolated CABG with CBP in Bursa Yüksek Ihtisas Training and Research Hospital between June 15 and October 15, 2019, were prospectively included in the study, which began after ethics approval was obtained. All patients signed an informed consent form prior to the operation. All procedures were performed in accordance with the Declaration of Helsinki. Preoperative demographic features, blood parameters, physical examination findings (height, weight, waist circumference $[W C]$ ), and operative (cross-clamp and CPB times) and postoperative data (PoAF status, hospital stay, intensive care hospitalization time) were recorded. Patients with known paroxysmal-persistent atrial fibrillation (AF), those using preoperative amiodarone, those with known systemic inflammatory disease, moderate to severe heart valve disease, a left atrium diameter $\geq 40 \mathrm{~mm}$, creatinine values $>1.5 \mathrm{mg} /$ $\mathrm{dL}$, patients who underwent acute coronary syndrome in the past month, emergency operations, those who underwent perioperative myocardial infarction, and who had intra-aortic balloon insertion were excluded. After the implementation of exclusion criteria, 199 patients were included in the study. The primary endpoint of the study was defined as the development of intra-hospital PoAF. Patients who did not develop in-hospital PoAF were identified as Group 1, and those who did constituted Group 2.

\section{Calculation of VAI}

Patients' heights and weights were measured while wearing a standard pre-surgical gown with a known weight. WC was measured from the midline between the iliac crest and the lower border of the lower rib while patients were standing. The blood parameter values were obtained from the preoperative routine tests and those of each patient were entered into the computer program. The following formulations were used for calculation ${ }^{[5]}$ :

$$
\begin{aligned}
& \text { Females: } \mathrm{VAI}=\left(\frac{\mathrm{WC}}{36.58 \times(1.89 \times \mathrm{BMI})}\right) \times\left(\frac{\mathrm{TG}}{0.81}\right) \times\left(\frac{1.52}{\mathrm{HDL}}\right) \\
& \text { Males: } \mathrm{VAI}=\left(\frac{\mathrm{WC}}{39.68 \times(1.88 \times \mathrm{BMI})}\right) \times\left(\frac{\mathrm{TG}}{1.03}\right) \times\left(\frac{1.31}{\mathrm{HDL}}\right)
\end{aligned}
$$

Where:

WC: $\mathrm{cm}$

BMl: $\mathrm{kg} / \mathrm{m}^{2}$

Triglycerides (TG): $\mathrm{mmol} / \mathrm{L}$

High-density lipoprotein (HDL): $\mathrm{mmol} / \mathrm{L}$

\section{Calculation of PNI}

The values obtained from the routine preoperative blood tests of the patients were used to calculate PNI with the formula below:

$\mathrm{PNI}=$ serum albumin level $(\mathrm{g} / \mathrm{L})+$ total lymphocyte count $\left(10^{3} / \mu \mathrm{L}\right) \times 5$

\section{Postoperative Rhythm Monitoring}

All patients were transferred to the cardiovascular surgery intensive care unit after the operation. During both inpatient and intensive care follow-ups, electrocardiography (ECG) monitoring was performed, and 12-lead ECG recordings were obtained daily. They were also obtained if patients reported complaints such as palpitations and sweating when they were not monitored in their beds. AF was defined as the absence of a P wave and the development of irregular ventricular rhythm before the QRS complex, and it was considered PoAF once it lasted over five minutes. Patients who developed PoAF were primarily treated with intravenous beta-blockers for rate control, and intravenous amiodarone was administered in patients who did not respond to beta-blocker therapy. Cardioversion was performed in patients with unstable hemodynamics after the abovementioned treatments. If the patient has been in AF for $>48$ hours and hemodynamic instability has developed, electrical cardioversion 
was performed following transesophageal echocardiography and exclusion of left atrial thrombus.

\section{Statistical Analysis}

In this study, statistical analyses were performed using the IBM Corp. Released 2012, IBM SPSS Statistics for Windows, Version 21.0, Armonk, NY: IBM Corp. statistical package program. The $P$-values obtained in the test results were considered significant when $<0.05$. Mean and standard deviations were calculated for continuous and ordinal data using descriptive methods. Kolmogorov-Smirnov and Shapiro-Wilk tests were used for evaluation of normality distribution. Student's t-test and MannWhitney $U$ test were used to assess normally and non-normally distributed data, respectively. Frequency and percentage analysis were conducted for nominal data, which were compared with Chi-square test. Multivariate regression analysis was performed to show the effects of PoAF risk factors (Model 1 with PNI and Model 2 with VAI). Receiver-operating characteristic (ROC) curve analysis was performed for VAI and PNI in terms of predicting PoAF and the areas under the curve (AUC) were calculated.

\section{RESULTS}

General characteristics of the patients included in the study are presented in Table 1. PoAF developed in 55 (27.6\%) patients
(Group 2). The mean age of the 144 patients included in Group 1 and 55 patients in Group 2 were $56.9 \pm 8.7$ and $64.3 \pm 10.2$ years, respectively $(P<0.001)$. The rates of hypertension $(H T)$ and COPD were higher in Group 2 ( $P=0.021, P=0.017$, respectively). The two groups were similar in terms of gender, coronary intervention history, diabetes mellitus, BMl, beta-blocker use, and angiotensinconverting enzyme inhibitor/angiotensin receptor blocker use.

Patients' preoperative laboratory values and perioperative features are summarized in Table 2. There was no significant difference between the groups in terms of white blood cell, neutrophil, low-density lipoprotein cholesterol, HDL cholesterol, and albumin values. In Group 2, lymphocyte values and PNI were significantly lower $(P=0.004, P=0.003$, respectively), whereas TG values, $C$-reactive protein, and VAI were significantly higher $(P=0.038, P=0.018, P<0.001$, respectively). Among operative data, the numbers of distal anastomoses, total perfusion, and crossclamp times were similar in both groups. Intensive care length of stay and hospitalization time were higher in the patient group who developed PoAF $(P<0.001)$.

Logistic regression analysis was performed to reveal the factors affecting PoAF occurring in the hospital. In univariate analysis, PoAF was found to significantly correlate with age (odds ratio [OR]: 1.151, 95\% confidence interval [Cl]: 1.008-1.244, $P<0.001$ ), HT (OR: 0.824, Cl: 0.756-0.978, $P=0.026)$, COPD (OR: 0.653, Cl: 0.312-0.776, $P=0.023$ ), lymphocyte counts (OR: 0.396,

Table 1. Patients' preoperative variables and demographic data.

\begin{tabular}{|c|c|c|c|}
\hline Characteristics & Group 1 & Group 2 & $P$-value \\
\hline & $(n=144)$ & $(n=55)$ & \\
\hline Age (years), mean $\pm S D$ & $56.9 \pm 8.7$ & $64.3 \pm 10.2$ & $<0.001^{\dagger}$ \\
\hline Male gender, n (\%) & $113(78.4)$ & $45(81.8)$ & $0.547^{*}$ \\
\hline Previous $\mathrm{PCl}, \mathrm{n}(\%)$ & $24(16.6)$ & $11(20)$ & $0.672^{*}$ \\
\hline Hypertension, n (\%) & $85(59.2)$ & $46(83.6)$ & $0.021^{*}$ \\
\hline COPD, n (\%) & $21(14.5)$ & $21(38.1)$ & $0.017^{*}$ \\
\hline $\mathrm{BMI}\left(\mathrm{kg} / \mathrm{m}^{2}\right)$ & $29.4 \pm 4.6$ & $30.4 \pm 6.1$ & $0.201^{\dagger}$ \\
\hline Diabetes mellitus, n (\%) & $30(20.8)$ & $13(23.6)$ & $0.779^{*}$ \\
\hline Smoking, n (\%) & $33(22.9)$ & $16(29)$ & $0.614^{*}$ \\
\hline Beta-blocker use, n (\%) & $35(24.3)$ & $10(18.1)$ & $0.572^{*}$ \\
\hline ACE-I/ARB use, n (\%) & $44(30.4)$ & $15(25.4)$ & $0.718^{*}$ \\
\hline Ejection fraction (\%), mean $\pm S D$ & $50.8 \pm 7.5$ & $48.3 \pm 6.6$ & $0.196^{\dagger}$ \\
\hline Left atrial diameter $(\mathrm{cm})$, mean $\pm S D$ & $3.5 \pm 0.3$ & $3.7 \pm 0.3$ & $0.228^{\dagger}$ \\
\hline EurOSCORE II & $1.6(0.5-4.8)$ & $1.8(0.5-5.2)$ & $0.189^{\ddagger}$ \\
\hline
\end{tabular}

\footnotetext{
tStudent's t-test

${ }^{*}$ Chi-square test

${ }^{\ddagger}$ Mann-Whitney $U$ test (data is expressed as median [interquartile range])

$A C E-I=$ angiotensin-converting enzyme inhibitor; $A R B=$ angiotensin receptor blocker; $B M l=b o d y$ mass index; $C O P D=c h r o n i c$ obstructive pulmonary disease; EuroSCORE II=European System for Cardiac Operative Risk Evaluation II; PCI=percutaneous coronary intervention; SD=standard deviation
} 
Table 2. Patients' preoperative laboratory values and perioperative variables.

\begin{tabular}{|c|c|c|c|}
\hline \multirow{2}{*}{ Characteristics } & Group 1 & Group 2 & \multirow{2}{*}{$P$-value } \\
\hline & $(n=144)$ & $(n=55)$ & \\
\hline Hemoglobin (g/dL) & $14.1(12.2-16)$ & $13.5(12.4-16.8)$ & $0.284^{\ddagger}$ \\
\hline White blood cell $\left(10^{3} / \mu \mathrm{L}\right)$ & $8(6.5-9.9)$ & $8(6.5-10.7)$ & $0.201^{\ddagger}$ \\
\hline Neutrophil $\left(10^{3} / \mu \mathrm{L}\right)$ & $4.4(3.5-9.7)$ & $4.7(3.6-9.9)$ & $0.267^{\ddagger}$ \\
\hline Lymphocyte $\left(10^{3} / \mu \mathrm{L}\right)$ & $2.2(0.8-3.9)$ & $1.8(0.7-3.8)$ & $0.004^{\ddagger}$ \\
\hline Creatinine $(\mathrm{mg} / \mathrm{dL})$ & $1.1(0.36-1.49)$ & $1.2(0.44-1.48)$ & $0.556^{\ddagger}$ \\
\hline LDL-C (mmol/L) & $3.3(2.3-4.6)$ & $3.5(3-4.8)$ & $0.216^{\ddagger}$ \\
\hline $\mathrm{HDL}-\mathrm{C}(\mathrm{mmol} / \mathrm{L})$ & $1(0.7-1.4)$ & $1.1(0.7-1.6)$ & $0.196^{\ddagger}$ \\
\hline Triglyceride (mmol/L) & $2(0.7-5.5)$ & $2.4(0.9-5.9)$ & $0.038^{\ddagger}$ \\
\hline C-reactive protein (mg/dL) & $7.4(1.6-38)$ & $9.1(1.9-40)$ & $0.018^{\ddagger}$ \\
\hline Albumin (g/L) & $39.2(35-53)$ & $38.7(34.4-54)$ & $0.212^{\ddagger}$ \\
\hline Free T3 (pg/mL) & $2.8(2.3-5.2)$ & $3(2.2-5.5)$ & $0.283^{\ddagger}$ \\
\hline Free T4 (ng/dL) & $0.7(0.5-1.2)$ & $0.8(0.5-1.3)$ & $0.678^{\ddagger}$ \\
\hline $\mathrm{TSH}(\mu \mathrm{U} / \mathrm{L})$ & $1.3(0.8-4)$ & $1.4(0.7-4.2)$ & $0.317^{\ddagger}$ \\
\hline VAl & $3.5(1.2-14.9)$ & $5.2(2.4-15)$ & $<0.001^{\neq}$ \\
\hline $\mathrm{PNI}$ & $48(35-69)$ & $45(34-58)$ & $0.003^{\ddagger}$ \\
\hline Distal anastomosis number, $\mathrm{n}$ & $4(1-6)$ & $4(2-6)$ & $0.393^{\ddagger}$ \\
\hline CCt (minutes) & $67(44-91)$ & $72(52-96)$ & $0.214^{\ddagger}$ \\
\hline TPt (minutes) & $96(70-130)$ & $120(93-138)$ & $0.302^{\ddagger}$ \\
\hline Total chest tube drainage (ml) & $450(250-1350)$ & $500(300-1400)$ & $0.418^{\ddagger}$ \\
\hline Inotropic support, n (\%) & $8(5.5)$ & $12(21.8)$ & $0.094^{*}$ \\
\hline ICU length of stay (days) & $2.5 \pm 1$ & $3.4 \pm 1.2$ & $<0.001^{\dagger}$ \\
\hline Total hospital length of stay (days) & $6.8 \pm 1.2$ & $8.5 \pm 1.2$ & $<0.001^{\dagger}$ \\
\hline
\end{tabular}

tStudent's t-test (data is expressed as mean \pm standard deviation)

‡Mann-Whitney $U$ test (data is expressed as median [interquartile range])

* Chi-square test

CCt=cross-clamp time; HDL-C=high-density lipoprotein cholesterol; ICU=intensive care unit; LDL-C=low-density lipoprotein cholesterol; $\mathrm{PNI}=$ prognostic nutritional index; TPt=total perfusion time; $\mathrm{TSH}=$ thyroid-stimulating hormone; $\mathrm{VAI}=\mathrm{visceral}$ adiposity index

Cl: 0.294-0.804, $P=0.010)$, C-reactive protein (OR: 1.050, Cl: $1.008-$ 1.212, $P=0.028)$, PNI (OR: 1.024, Cl: 1.010-1.196, $P=0.002)$, and VAl (OR: 1.412, Cl: 1.186-1.697, $P<0.001$ ), and not correlate with TG levels. In multivariate analysis Model 1, age (OR: 1.084, Cl: 1.0101.176, $P=0.009$ ), COPD (OR: 0.798, Cl: 0.664-0.928, $P=0.048$ ), and PNI (OR: 1.052, Cl: 1.015-1.379, $P=0.011)$ were determined as independent predictors for PoAF. In Model 2, age (OR: 1.078, Cl: 1.008-1.194, $P=0.012$ ), lymphocyte counts (OR: $0.412, \mathrm{Cl}$ : 0.374$0.778, P=0.032)$, and VAI (OR: 1.516, Cl: 1.314-2.154, $P<0.001)$ were determined as independent predictors for PoAF.

ROC curve analysis revealed that the cutoff values for VAl ratio and PNI were 3.59 (AUC: 0.733, 95\% Cl: 0.641-0.824, $P<0.001$,
84.6\% sensitivity and $53.1 \%$ specificity) (Figure 1) and 43.7 (AUC: $0.681,95 \% \mathrm{Cl}: 0.574-0.788, P=0.002,76.4 \%$ sensitivity and $48.3 \%$ specificity) (Figure 2).

\section{DISCUSSION}

$A F$, which occurs after $C A B G$, is undesired due to mortality, cerebrovascular events, heart failure, and the financial burden caused by prolonged hospitalization ${ }^{[9]}$. Many studies have been and are currently conducted to reveal possible risk factors for this condition. Although they have been extensively studied in other areas of medicine, in this prospective study, we explored the roles 


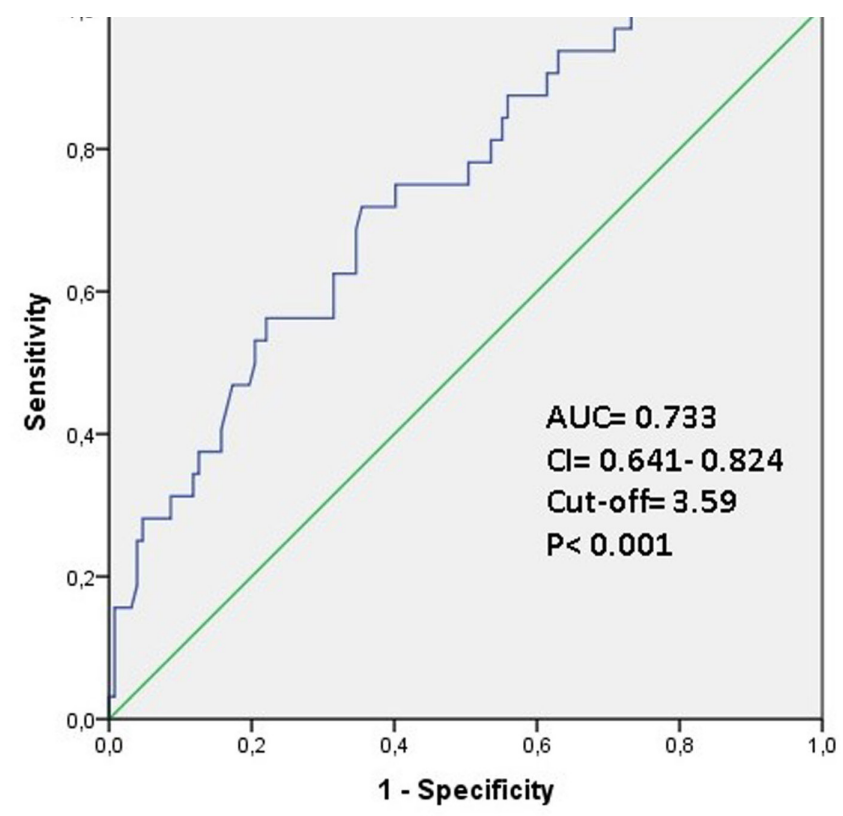

Fig. 1 - Data figure of the area under the curve (AUC), confidence interval (CI), and cutoff values in receiver-operating characteristic (ROC) curve analysis for visceral adiposity index (84.6\% sensitivity, $53.1 \%$ specificity).

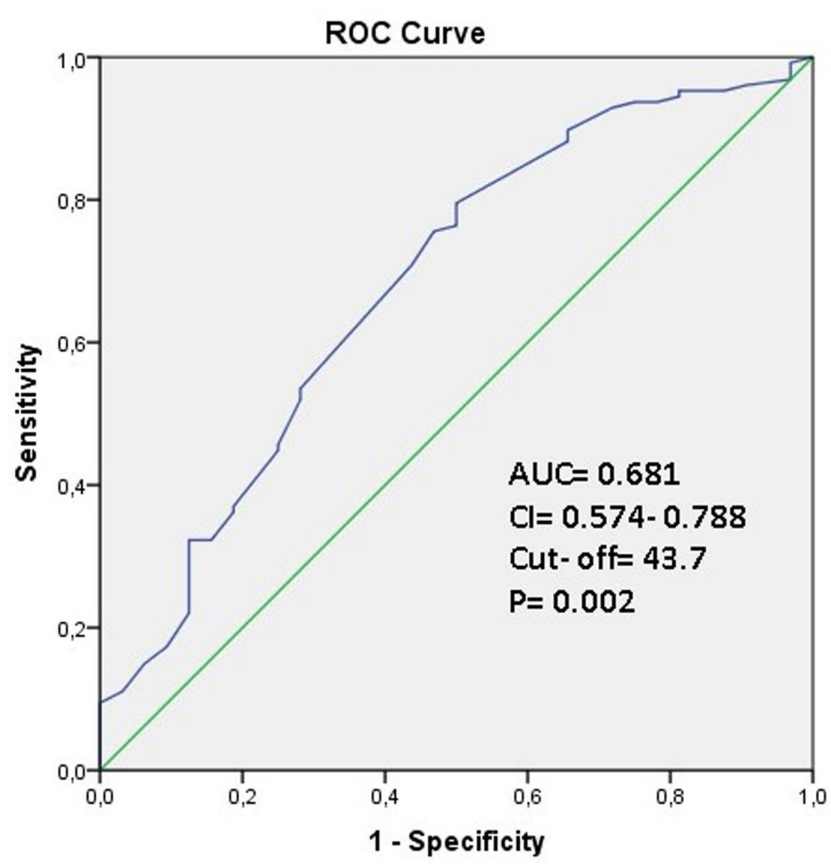

Diagonal segments are produced by ties.

Fig. 2 - Data figure of the area under the curve (AUC), confidence interval (CI), and cutoff values in receiver-operating characteristic (ROC) curve analysis for prognostic nutritional index (76.4\% sensitivity, 48.3\% specificity). of PNI and VAI values in predicting PoAF after CABG operations and determined that low PNI and high VAl were independent predictors for PoAF.

Obesity has become one of the most important problems of our era, as humans switched to office-style living. Cardiovascular diseases are the leading problems caused by this situation. Obesity can also affect undesired outcomes such as PoAF after treatments like CABG. BMI is the most commonly used parameter as an indicator of obesity. In a meta-analysis conducted by Hernandez et al. ${ }^{[3]}$ in 2013, obesity (defined by BMI) was reported as a risk factor of PoAF, regardless of the type of cardiac surgery. In the meta-analysis of Aune et al. ${ }^{[10]}$ involving prospective studies on general population, BMI and WC were found to be associated with AF. However, in this study, AF was more frequent in the group with a BMI value of $20 \mathrm{~kg} / \mathrm{m}^{2}$ compared to the group with BMI values between 22 and $24 \mathrm{~kg} / \mathrm{m}^{2}$. In parallel with this finding, although obesity was found to affect the development of cardiovascular diseases in recent studies, it has been reported that overweight and mildly obese patients with cardiovascular disease have a better prognosis than low or normal weight patients ${ }^{[11,12]}$. Consequently, WC value, which is thought to be more valuable in the formation and prognosis of cardiovascular diseases, have been the subject of research. It is an important indicator of central obesity and has been shown to be a risk factor for $\mathrm{AF}^{[13]}$. In another study, it was found that central obesity may be more valuable than BMI in predicting PoAF after $C A B G^{[14]}$. In a retrospective study conducted by Girerd et al. ${ }^{[15]}$, WC of 102 $\mathrm{cm}$ and above was reported as an independent predictor for PoAF after CABG in men (OR: 1.40, P=0.04).

$\mathrm{VAl}$, calculated by formulating parameters such as WC, BMI, $\mathrm{TG}$, and $H D L$, is a valuable indicator of visceral fattening, and calculated with separate formulas for women and men. In a study conducted on general population, the rate of visceral adipose tissue was found to be more predictive for cardiovascular risks compared to BMI and WC ${ }^{[16]}$. In another study of 1498 patients, VAl was found to be an independent predictor for cardiovascular and cerebrovascular events, and VAI was reported as a more sensitive and specific predictor than its component $s^{[5]}$. Increased VAl values were also associated with cardiovascular events in a large population case-control study ${ }^{[17]}$. In light of all this information, we also determined VAI as an independent predictor in predicting PoAF after isolated CABG.

Malnutrition is an important public health problem in developed countries. PNI is a valuable malnutrition parameter obtained by adding five times the lymphocyte counts to the serum albumin value. Hypoalbuminemia is closely related to malnutrition and a good predictor for surgical risk. It has also been shown as an independent predictor of many cardiovascular diseases, including heart failure, coronary artery disease, and stroke. The importance of albumin stems from its antiinflammatory, antioxidant, and anticoagulant properties and its effects on osmotic pressure ${ }^{[18]}$. Lymphopenia is associated with major adverse events in atherosclerotic cardiovascular diseases ${ }^{[19]}$. The importance of high neutrophil/lymphocyte ratio in predicting prognosis after CABG is known and many studies are available on this subject ${ }^{[20]}$. The increase of this ratio is due to decreased lymphocyte count along with elevated neutrophil 
Table 3. Logistic regression analysis to identify factors affecting postoperative atrial fibrillation.

\begin{tabular}{|c|c|c|c|c|c|c|}
\hline \multirow{3}{*}{ Variables } & \multicolumn{3}{|c|}{ Univariate analysis } & \multicolumn{3}{|c|}{ Multivariate analysis } \\
\hline & $P$-value & $\operatorname{Exp}(B)$ & $95 \% \mathrm{Cl}$ & $P$-value & $\operatorname{Exp}(B)$ & $95 \% \mathrm{Cl}$ \\
\hline & & Odds ratio & Lower-upper & & Odds ratio & Lower-upper \\
\hline \multirow{2}{*}{ Age } & \multirow{2}{*}{$<0.001$} & \multirow{2}{*}{1.151} & \multirow{2}{*}{$1.008-1.244$} & $0.009^{a}$ & $1.084^{\mathrm{a}}$ & $1.010-1-176^{a}$ \\
\hline & & & & $0.012^{b}$ & $1.078^{b}$ & $1.008-1.194^{b}$ \\
\hline \multirow{2}{*}{ Hypertension } & \multirow{2}{*}{0.026} & \multirow{2}{*}{0.824} & \multirow{2}{*}{$0.756-0.978$} & $0.096^{\mathrm{a}}$ & $0.876^{\mathrm{a}}$ & $0.794-1.100^{a}$ \\
\hline & & & & $0.112^{b}$ & $0.914^{b}$ & $0.678-1.145^{b}$ \\
\hline \multirow{2}{*}{ COPD } & \multirow{2}{*}{0.023} & \multirow{2}{*}{0.653} & \multirow{2}{*}{$0.312-0.776$} & $0.048^{a}$ & $0.798^{\mathrm{a}}$ & $0.664-0.928^{a}$ \\
\hline & & & & $0.114^{b}$ & $0.678^{b}$ & $0.479-1.217^{b}$ \\
\hline Triglyceride & 0.064 & 0.897 & 0.674-1.010 & -- & -- & -- \\
\hline \multirow{2}{*}{ Lymphocyte } & \multirow{2}{*}{0.010} & \multirow{2}{*}{0.396} & \multirow{2}{*}{$0.294-0.804$} & - & - & - \\
\hline & & & & $0.032^{b}$ & $0.412^{b}$ & $0.374-0.778^{b}$ \\
\hline \multirow{2}{*}{ CRP } & \multirow{2}{*}{0.028} & \multirow{2}{*}{1.050} & \multirow{2}{*}{$1.008-1.212$} & $0.108^{a}$ & $1.090^{\mathrm{a}}$ & $0.928-1.234^{a}$ \\
\hline & & & & $0.176^{b}$ & $1.078^{b}$ & $0.879-1.194^{b}$ \\
\hline PNI & 0.002 & 1.024 & $1.010-1.196$ & $0.011^{a}$ & $1.052^{\mathrm{a}}$ & $1.015-1.379^{a}$ \\
\hline VAI & $<0.001$ & 1.412 & $1.186-1.697$ & $<0.001^{b}$ & $1.516^{b}$ & $1.314-2.154^{b}$ \\
\hline
\end{tabular}

aMultivariate analysis Model 1 (the goodness of fit of the model was confirmed by a P-value of 0.695 in the Hosmer-Lemeshow test) ${ }^{b}$ Multivariate analysis Model 2 (the goodness of fit of the model was confirmed by a P-value of 0.741 in the Hosmer-Lemeshow test) $\mathrm{Cl}=$ confidence interval; $\mathrm{COPD}=$ chronic obstructive pulmonary disease; $\mathrm{CRP}=\mathrm{C}$-reactive protein; $\mathrm{PNI}=$ prognostic nutritional index; $\mathrm{VAl}=$ visceral adiposity index

count. As a result, the number of $5 x$ lymphocytes used in PNI calculation appears to be a valuable parameter.

There are studies showing the prognostic significance of PNI value, an easily and rapidly calculable parameter which yields valuable information about nutritional status, in malignancy and hemodialysis patients ${ }^{[21,22]}$. In infants under the age of 18 months who underwent open heart surgery, it has been found to be associated with prolonged intensive care hospitalizations and poor postoperative outcome ${ }^{[23]}$. Yost et al. ${ }^{[24]}$ found it effective in predicting one-year survival in patients with a left ventricular support device. In that study, its effect on the development of early right ventricular failure following the operation was also reported.

The most recent study investigating the importance of PNI in patients undergoing cardiac surgery with CPB was published in the last months of 2019, in which 374 patients were retrospectively included. PNI cutoff value was determined as 46.13, and patients were divided into two groups as those with a high $(<46.13)$ and low risk (> 46.13). Early mortality and morbidity were significantly higher in the high-risk group $(9.0 \%$ vs. $2.9 \%$ : $P=.02,58.0 \%$ vs. $42.0 \%: P=.01$, respectively). In addition, multivariate analysis showed that $\mathrm{PNI}$ was an independent predictor of early mortality. Based on these results, the authors suggested that the value of PNI, which can be easily calculated preoperatively, is a valuable parameter in predicting early results in patients undergoing cardiac surgery with $\mathrm{CPB}^{[25]}$. In our study, we determined $\mathrm{PNI}$ as an independent predictor in predicting PoAF, one of the important causes of morbidity after CABG. However, VAI was more predictive than PNI.

Advanced age is a risk factor for PoAF. There is an increase in the AF incidence due to structural shifts in the heart and atrial fibrosis related to the advanced age. Also, COPD is a known predictor of $\mathrm{POAF}^{[6]}$. In our current study, advanced age was found to be an independent predictor of PoAF in multivariate Model 1 and Model 2. And COPD was found to be an independent predictor in Model 1.

\section{Limitations}

The fact that this is a single center study with a low sample size is the most important limitation. Although PNI and VAI had good sensitivity, they had low specificity. Further prospective studies with a larger number of patients are required.

\section{CONCLUSION}

PoAF, which occurs after CABG, is particularly important due to possible mortality and morbidity outcomes. Predicting the possible risk factors of this condition is highly valuable for cardiac surgeons, and many studies have been done in this field. In this study, we determined that low PNI, a simply calculable and cheap parameter, along with high VAI were risk factors for PoAF. Physical examination evaluations of height, weight, and body surface area 
are routinely performed before cardiac surgery. However, WC measurement is not a routine assessment for cardiac surgeons. WC may become a parameter in our routine examination if our research is supported by larger scale new studies.

\section{No financial support. \\ No conflict of interest.}

\section{Authors' roles \& responsibilities}

ME Substantial contributions to the conception or design of the work; or the acquisition, analysis, or interpretation of data for the work; agreement to be accountable for all aspects of the work in ensuring that questions related to the accuracy or integrity of any part of the work are appropriately investigated and resolved; drafting the work or revising it critically for important intellectual content; final approval of the version to be published

KKO Substantial contributions to the conception or design of the work, or the acquisition, analysis, or interpretation of data for the work; final approval of the version to be published

MS Substantial contributions to the conception or design of the work; or the acquisition, analysis, or interpretation of data for the work; final approval of the version to be published

OG Substantial contributions to the conception or design of the work; or the acquisition, analysis, or interpretation of data for the work; final approval of the version to be published

SY Drafting the work or revising it critically for important intellectual content; final approval of the version to be published

AFO Drafting the work or revising it critically for important intellectual content; final approval of the version to be published

\section{REFERENCES}

1. Jaimes MC, Torrado LAA, Reyes NFS, Mackenzie JC, Mallarino JPU. Hypothyroidism is a risk factor for atrial fibrillation after coronary artery bypass graft. Braz J Cardiovasc Surg. 2017;32(6):475-80. doi:10.21470/1678-9741-2017-0080.

2. Hernández-Leiva E, Alvarado P, Dennis RJ. Postoperative atrial fibrillation: evaluation of its economic impact on the costs of cardiac surgery. Braz J Cardiovasc Surg. 2019;34(2):179-86. doi:10.21470/1678-9741-2018-0218.

3. Hernandez AV, Kaw R, Pasupuleti V, Bina P, loannidis JP, Bueno H, et al. Association between obesity and postoperative atrial fibrillation in patients undergoing cardiac operations: a systematic review and meta-analysis. Ann Thorac Surg. 2013;96(3):1104-16. doi:10.1016/j. athoracsur.2013.04.029.

4. Yusuf S, Hawken S, Ounpuu S, Bautista L, Franzosi MG, Commerford P, et al. Obesity and the risk of myocardial infarction in 27,000 participants from 52 countries: a case-control study. Lancet. 2005;366(9497):1640-9. doi:10.1016/S0140-6736(05)67663-5.

5. Amato MC, Giordano C, Galia M, Criscimanna A, Vitabile S, Midiri M, et al. Visceral adiposity index: a reliable indicator of visceral fat function associated with cardiometabolic risk. Diabetes Care. 2010;33(4):920-2. doi:10.2337/dc09-1825.
6. Erdolu B, As AK, Engin M. The relationship between the HATCH score, neutrophil to lymphocyte ratio and postoperative atrial fibrillation after off-pump coronary artery bypass graft surgery. Heart Surg Forum. 2020;23(1):E088-92. doi:10.1532/hsf.2771.

7. Keskin M, Hayıroğlu MI, Keskin T, Kaya A, Tatlısu MA, Altay S, et al. A novel and useful predictive indicator of prognosis in ST-segment elevation myocardial infarction, the prognostic nutritional index. Nutr Metab Cardiovasc Dis. 2017;27(5):438-46. doi:10.1016/j.numecd.2017.01.005.

8. Teker Açıkel ME, Korkut AK. Impact of controlling nutritional status score (CONUT) and prognostic nutritional index (PIN) on patients undergoing coronary artery bypass graft surgery. Heart Surg Forum. 2019;22(4):E294-7. doi:10.1532/hsf.2493.

9. Feguri GR, Franco AC. Postoperative metabolic, inflammation, and atrial fibrillation control: a relentless battle. Braz J Cardiovasc Surg. 2019;34(2):VI-VII. doi:10.21470/1678-9741-2018-0404.

10. Aune D, Sen A, Schlesinger S, Norat T, Janszky I, Romundstad P, et al. Body mass index, abdominal fatness, fat mass and the risk of atrial fibrillation: a systematic review and dose-response meta-analysis of prospective studies. Eur J Epidemiol. 2017;32(3):181-92. doi:10.1007/ s10654-017-0232-4.

11. Lavie CJ, De Schutter A, Parto P, Jahangir E, Kokkinos P, Ortega FB, et al. Obesity and prevalence of cardiovascular diseases and prognosisthe obesity paradox updated. Prog Cardiovasc Dis. 2016;58(5):537-47. doi:10.1016/j.pcad.2016.01.008.

12. Lavie CJ, McAuley PA, Church TS, Milani RV, Blair SN. Obesity and cardiovascular diseases: implications regarding fitness, fatness, and severity in the obesity paradox. J Am Coll Cardiol. 2014;63(14):1345-54. doi:10.1016/j.jacc.2014.01.022.

13. Frost L, Benjamin EJ, Fenger-Grøn M, Pedersen A, Tjønneland A, Overvad K. Body fat, body fat distribution, lean body mass and atrial fibrillation and flutter. A Danish cohort study. Obesity (Silver Spring). 2014;22(6):1546-52. doi:10.1002/oby.20706.

14. Echahidi N, Mohty D, Pibarot P, Després JP, O'Hara G, Champagne J, et al. Obesity and metabolic syndrome are independent risk factors for atrial fibrillation after coronary artery bypass graft surgery. Circulation. 2007;116(11 Suppl):I213-9. doi:10.1161/CIRCULATIONAHA.106.681304.

15. Girerd N, Pibarot P, Fournier D, Daleau P, Voisine P, O'Hara G, et al. Middle-aged men with increased waist circumference and elevated C-reactive protein level are at higher risk for postoperative atrial fibrillation following coronary artery bypass grafting surgery. Eur Heart J. 2009;30(10):1270-8. doi:10.1093/eurheartj/ehp091.

16. Britton KA, Massaro JM, Murabito JM, Kreger BE, Hoffmann U, Fox CS. Body fat distribution, incident cardiovascular disease, cancer, and allcause mortality. J Am Coll Cardiol. 2013;62(10):921-5. doi:10.1016/j. jacc.2013.06.027.

17. Zhang X, Shu XO, Li H, Yang G, Xiang YB, Cai Q, et al. Visceral adiposity and risk of coronary heart disease in relatively lean Chinese adults. Int J Cardiol. 2013;168(3):2141-5. doi:10.1016/j.ijcard.2013.01.275.

18. Arques S. Human serum albumin in cardiovascular diseases. Eur J Intern Med. 2018;52:8-12. doi:10.1016/j.ejim.2018.04.014.

19. Núñez J, Sanchis J, BodíV, Núñez E, Mainar L, Heatta AM, et al. Relationship between low lymphocyte count and major cardiac events in patients with acute chest pain, a non-diagnostic electrocardiogram and normal troponin levels. Atherosclerosis. 2009;206(1):251-7. doi:10.1016/j. atherosclerosis.2009.01.029.

20. Gurbuz O, Kumtepe G, Ozkan H, Karal IH, Velioglu Y, Ercan A, et al. Predictive value of neutrophil-lymphocyte ratio for long-term cardiovascular event following coronary artery bypass grafting. Braz J Cardiovasc Surg. 2020;35(3):274-84. doi:10.21470/1678-9741-2018-0362.

21. Kang SH, Cho KH, Park JW, Yoon KW, Do JY. Onodera's prognostic nutritional index as a risk factor for mortality in peritoneal dialysis patients. J Korean Med Sci. 2012;27(11):1354-8. doi:10.3346/jkms.2012.27.11.1354. 
22. Geng Y, Qi Q, Sun M, Chen H, Wang P, Chen Z. Prognostic nutritional index predicts survival and correlates with systemic inflammatory response in advanced pancreatic cancer. Eur J Surg Oncol. 2015;41(11):1508-14. doi:10.1016/j.ejso.2015.07.022.

23. Wakita M, Fukatsu A, Amagai T. Nutrition assessment as a predictor of clinical outcomes for infants with cardiac surgery: using the prognostic nutritional index. Nutr Clin Pract. 2011;26(2):192-8. doi:10.1177/0884533611399922.
24. Yost G, Tatooles A, Bhat G. Preoperative nutritional assessment with the prognostic nutrition index in patients undergoing left ventricular assist device implantation. ASAIO J. 2018;64(1):52-5. doi:10.1097/ MAT.0000000000000625.

25. Lee SI, Ko KP, Choi CH, Park CH, Park KY, Son KH. Does the prognostic nutritional index have a predictive role in the outcomes of adult cardiac surgery? JThorac Cardiovasc Surg. 2020;160(1):145-53.e3. doi:10.1016/j. jtcvs.2019.08.069. 